\title{
Migration of a self expandable metallic stent in malignant esophageal-pleural fistula - A complication that needs active surveillance
}

\author{
Neeraj Singla ${ }^{1}$, Monica Gupta ${ }^{1}$, Sanjay D Cruz ${ }^{1}$, Ravinder Kaur ${ }^{2}$ \\ 1. Department of Medicine, Government Medical College and Hospital, Chandigarh, India. 2. Department of Radiology, \\ Government Medical College and Hospital, Chandigarh, India.
}

Correspondence: Monica Gupta. Address: Department of Medicine, Government Medical College and Hospital, Sector 32, Chandigarh - 160030, India. Email: monicamanish2001@gmail.com

Received: August 5, 2014

DOI : $10.5430 /$ crim.v2n1p19
Accepted: September 1, $2014 \quad$ Online Published: September 15, 2014

URL: http://dx.doi.org/10.5430/crim.v2n1p19

\begin{abstract}
Development of malignant esophago-pleural fistulas is relatively rare but life-threatening complication. We present a 50 year-old female patient with 6 months history of distal esophageal carcinoma. Patient presented with right sided chest pain, dysphagia, dyspnoea, cough and fever. Right side pyopneumothorax was diagnosed and intercostal drainage (ICD) tube was inserted. Presence of food material in the drainage bag led to the diagnosis of oesophageal-pleural fistula. Self expandable stent was placed, however 1 month later stent migration was observed and patient expired due to worsening pyopneumothorax and sepsis.
\end{abstract}

\section{Keywords}

Esophageal carcinoma, Esophageal stents, Esophageal-pleural fistulas, Stent migration

\section{I ntroduction}

Patients with esophageal malignancy are especially prone to develop pathologic communication between esophagus and adjacent structures. This complication is called a malignant esophageal fistula ${ }^{[1]}$. The occurrence of such fistulas is $10 \%-15 \%$ and life span is less than 7 weeks in patients who do not undergo treatment ${ }^{[2-4]}$. In patients with esophageal cancer, incidence of malignant esophageal-pleural fistula (EPF) is $5 \%-15 \%{ }^{[5,6]}$. In patients with EPF, who do not undergo treatment develop an unremitting respiratory tract flawing, consequently leading to pulmonary sepsis and death, as a result there is difficulty in making early diagnosis and timely treatment. Esophageal stent placement has been used to manage esophageal fistulas ${ }^{[7,8]}$. Due to their lesser complications, self-expanding metallic stents are used in majority of patients ${ }^{[9]}$. We present a 50 year-old female with carcinoma of esophagus who developed an esophageal pleural fistula after receiving 3 cycles of external beam radiotherapy and 6 cycles of palliative chemotherapy and later had stent migration.

\section{Case presentation}

A 50-year-old female was admitted in our medical unit with a diagnosis of distal esophageal adeno-carcinoma of 6 month duration. CT thorax was suggestive of circumferential asymmetrical mural thickening involving $10-11 \mathrm{~cm}$ long segment of 
distal third of intra-thoracic esophagus; adjacent to gastro-esophageal junction. Upper GI Endoscopy showed prominent ulcerous-nodular growth occupying 3/4th of circumference in distal end of esophagus. Patient had received 3 cycles of external beam radiotherapy and 6 cycles of palliative chemotherapy, after that she lost to follow-up.

Currently, she presented with right side chest pain, dysphagia and dyspnoea associated with high grade fever and decreased appetite. There was no history of hematemesis or blood in sputum. On general examination, patient had pallor, no icterus, was normotensive with blood pressure of 110/70 mm Hg and had tachypnea. Chest examination revealed decreased air entry and vocal resonance on right side. Rest of the systemic examination was unremarkable.

\subsection{I nvestigations}

During the course of investigations, hemoglobin was $7.8 \mathrm{~g} / \mathrm{dl}$, total leukocyte count was $16,000 / \mathrm{mm}^{3}$, platelets were $160,000 / \mathrm{mm}^{3}$; no abnormality was seen in liver and renal function tests. Chest $\mathrm{x}$-ray was suggestive of right sided pyopneumothorax. Upper gastrointestinal endoscopy revealed ulceration at 27-39 cm, scope was easily negotiable, some mucosal irregularities were present; but there was no substantiation of fistula.

\subsection{Management}

Right sided pyopneumothorax was managed by insertion of inter-costal drainage tube (ICD), following patient's condition improved gradually. However after a week, food material was noticed in the chest tube drainage bag; consequently a barium swallow with urograffin $76 \%$ was carried out. Barium study revealed presence of irregular marginated fistulous tract from the lower end of oesophagus (just above gastro-esophageal junction) communicating with right pleural cavity (see Figure 1). Palliative management was planned. Upper gastrointestinal endoscopy was repeated and a covered antireflux self expandable metallic stent (SEMS) Boston measuring $14 \mathrm{~cm}$ was placed across the growth (see Figure 2). Following this procedure, patient’s condition steadily improved and she was discharged after a week.

However she was again hospitalized after one month with progressive dyspnea; food material was observed again in drainage bag. A repeat barium study exposed another fistulous tract between the lower thoracic esophagus and right pleural cavity just above the level of upper margin of esophageal stent i.e. stent migration (see Figure 3). Re-intervention was planned but unfortunately patient expired due to deteriorating pyopneumothorax and sepsis.

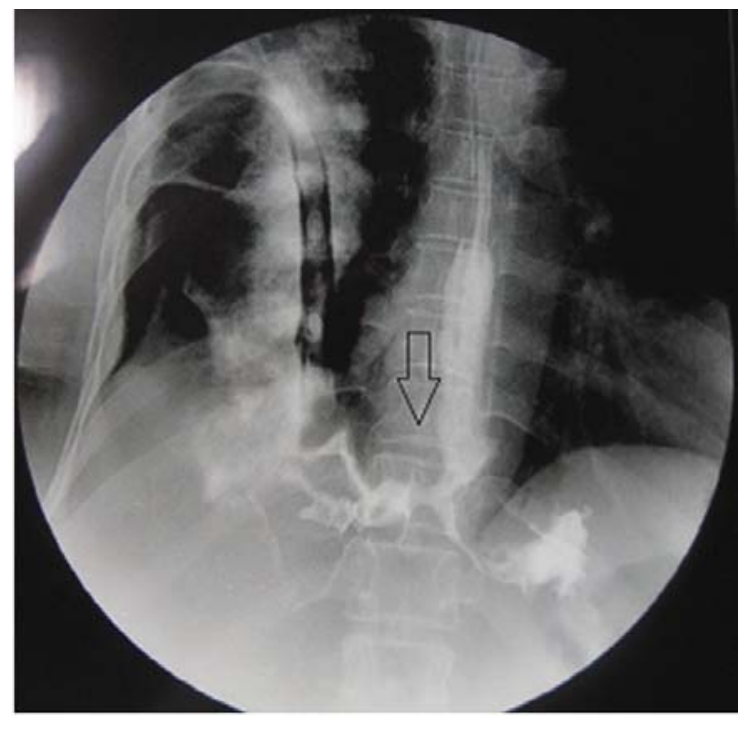

Figure 1. Barium swallow showing fistulous track from lower end of esophagus to right pleural cavity

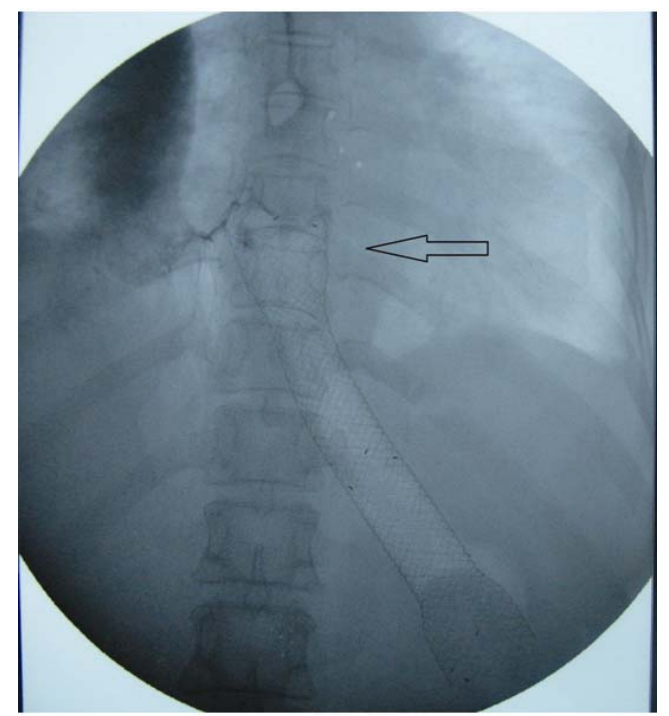

Figure 2. Covered self expandable metallic stent in-situ 


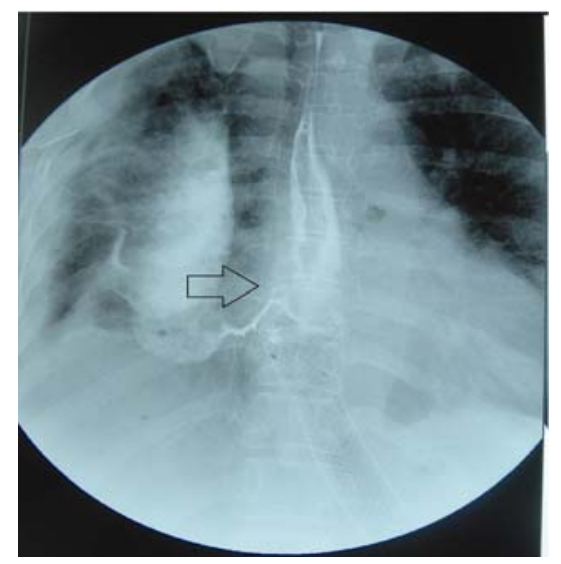

Figure 3. Barium Swallow showing fistulous tract from lower thoracic esophagus with right pleural cavity just above the level of upper margin of esophageal stent

\section{Discussion}

Esophago-pleural fistulas have a propensity to develop in extremely later stages of esophageal cancer, when remedial surgery is no longer considered. Causes of esophageal-pleural fistula include direct tumor incursion and ensuing perforation or consequence of radiation therapy, laser therapy, chemotherapy, or pre-existing stents ${ }^{[2]}$. To decrease mortality, the diagnosis of esophago-pleural fistulas should be made timely; superlatively before the inception of pneumonia or lung abscesses.

The scope of treatment modalities anticipated by different authors varies from palliative to dynamic and, if feasible, major surgical interventions. Surgical treatment has been related with considerable morbidity and an extremely high mortality rate. Esophageal stenting seems to be the most reasonable palliative measure, with $80 \%-100 \%$ effectiveness of covered self expanding metal stents reported in recent studies ${ }^{[6]}$. In $80 \%$ of cases, after placement of the stent there is complete closure of the fistula, nevertheless complications are familiar ${ }^{[2]}$; which comprise of unrelenting chest pain, tracheal or esophageal mucosa necrosis due to pressure, development of granulation tissue causing stenosis, dyspnoea due to compression of the trachea, perforation, hemorrhage (which may be apparent as hemoptysis or hematemesis) and stent

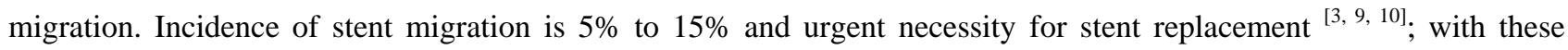
logistics, tumor in-growth through the stent metal in majority of patients with malignant esophageal fistulas covered stents are used as the cover prevent mesh ${ }^{[11]}$.

Conversely, the utilization of covered stents is beleaguered by stent migration. When covered stents are placed for tumors of the distal esophagus or gastric cardia, stent migration is more prone to happen then stents placed for more proximally located tumors since the distal portion of stents projects liberally into the gastric fundus without any fixation to wall of esophagus ${ }^{[12]}$. As a result, stent migration is documented in up to $28 \%$ of patients in which covered stent is used ${ }^{[13,14]}$. A migrated esophageal stent, irrespective of manifestations, should be observed thoroughly and removed instantaneously. Endoscopic clipping ${ }^{[15]}$ can reduce the hazard of stent migration, especially in those related with esophago-pleural fistulas without luminal obstruction. Covered SEMS with an anti-migration system ${ }^{[16]}$ with uncovered long flared ends has a longer life and lesser risk of migration; therefore they are beneficial in the palliative treatment of patients.

\section{Learning points}

In patient with carcinoma of esophagus presenting late with sudden onset chest symptoms, esophageal-pleural fistula should be considered as a differential. Esophageal-pleural fistula should be managed early with appropriate techniques to 
prevent systemic complications. Migrations of SEMS are serious and overlooked complication in malignant esophagealpleural fistula. Thus, placements of these stents need expertise and close monitoring during follow up. Newer anti-migration methods like endoscopic clips, long uncovered flared ends aids in prevention of stent migration.

\section{References}

[1] Campion JP, Bourdelat D, Launois B. Surgical treatment of malignant esophago-tracheal fistulas. Am J Surg. 1983; 146: 641-646. http://dx.doi.org/10.1016/0002-9610(83)90303-3

[2] Shin JH, Song HY, Ko GY, et al. Esophago-respiratory fistula: long-term results of palliative treatment with covered expandable metallic stents in 61 patients. Radiology. 2004; 232: 252-259. http://dx.doi.org/10.1148/radiol.2321030733

[3] Belleguic C, Lena H, Briens E, et al. Tracheo-bronchial stenting in patients with esophageal cancer involving the central airways. Endoscopy. 1999; 31: 232-236. http://dx.doi.org/10.1055/s-1999-13674

[4] Nasser A, Migliore M, Skinner D. Esophageal carcinoma with airway invasion. Chest. 1994; 106: 742-745. http://dx.doi.org/10.1378/chest.106.3.742

[5] Duranceau A, Jamieson GG. Malignant trachea-esophageal fistula. Ann Thorac Surg. 1984; 37: 346-354. http://dx.doi.org/10.1016/S0003-4975(10)60745-X

[6] Sarper A, Oz N, Cihangir C, et al. The efficacy of self expanding metal stents for palliation of malignant esophageal strictures and fistulas. Eur J CardiothoracSurg. 2003; 23: 794-798. http://dx.doi.org/10.1016/S1010-7940(03)00091-5

[7] Cwikiel W, Stridbeck H, Tranberg KG, et al. Malignant esophageal strictures: treatment with a self-expanding nitinol stent. Radiology. 1993; 187: 661-665. PMid:7684528 http://dx.doi.org/10.1148/radiology.187.3.7684528

[8] Ott C, Ratiu N, Endlicher E, et al. Self-expanding Polyflex plastic stents in esophageal disease: various indications, complications and outcomes. SurgEndosc. 2007; 21: 889-896. PMid:17177084 http://dx.doi.org/10.1007/s00464-006-9067-x

[9] Kvale PA, Simoff M, Prakash UBS. Palliatives care. Chest. 2003; 123: 284S-311S. PMid:12527586 http://dx.doi.org/10.1378/chest.123.1_suppl.284S

[10] Becker HD. Implantation of silicone stents. J Bronchol. 1998; 5: 175-176. http://dx.doi.org/10.1097/00128594-199804000-00020

[11] Morgan RA, Ellul JP, Denton ER, et al. Malignant esophageal fistulas and perforations: management with plastic-covered metallic endoprostheses. Radiology. 1997; 204: 527-532. PMid:9240548 http://dx.doi.org/10.1148/radiology.204.2.9240548

[12] Saxon RR, Barton RE, Katon RM, et al. Treatment of malignant esophagorespiratory fistulas with silicone-covered metallic Z stents. J VascIntervRadiol. 1995; 6: 237-242. http://dx.doi.org/10.1016/S1051-0443(95)71104-6

[13] Saxon RR, Morrison KE, Lakin PC, et al. Malignant esophageal obstruction and esophagorespiratory fistula: palliation with a polyethylene-covered Z-stent. Radiology. 1997; 202: 349-354. PMid:9015055 http://dx.doi.org/10.1148/radiology.202.2.9015055

[14] Wang MQ, Sze DY, Wang ZP, et al. Delayed complications after esophageal stent placement for treatment of malignant esophageal obstructions and esophagorespiratory fistulas. J VascIntervRadiol. 2001; 12: 465-474. http://dx.doi.org/10.1016/S1051-0443(07)61886-7

[15] Kato H, Fukuchi M, Miyazaki T, et al. Endoscopic clips prevent self-expandable metallic stent migration. Hepatogastroenterology. 2007; 54: 1388-90. PMid:17708260

[16] Kitano M, Yamashita Y, Tanaka K, et al. Covered self-expandable metal stents with an anti-migration system improve patency duration without increased complications compared with uncovered stents for distal biliary obstruction caused by pancreatic carcinoma: a randomized multicenter trial. Am J Gastroenterol. 2013; 108(11): 1713-22. PMid:24042190 http://dx.doi.org/10.1038/ajg.2013.305 